\title{
REVIEWS
}

\section{Casualty, accident and emergency, or emergency medicine, the evolution}

\author{
M Sakr, J Wardrope
}

Hospitals have always had to make arrangements for those who arrive at their doors seeking help. Over the years the numbers and complexity of problems presenting in this way have increased at an exponential rate. This increase in demand has been managed in different ways in different countries but in North America, Australia, some parts of Europe and the United Kingdom a new medical specialty has evolved, that of accident and emergency (A\&E) medicine (UK) or emergency medicine. This article will examine the evolution of the specialty in the United Kingdom and also look at the possible future changes in the scope of the specialty.

The A\&E department is the "shop window" of acute hospitals. It is the part of the hospital most closely in contact with the public as it offers the most informal access. ${ }^{1}$

It plays the most important part in caring for the acutely ill and injured patients. Also it is surrounded by so much drama, tragedy, and media interest.

The department and specialty are a rich subject for programmes, debates and criticism; if Shakespeare had been a doctor he would surely have worked in the A\&E department. ${ }^{2}$

What are the origins of our specialty, what has made it successful and what lessons of the past should we not forget when planning our future?

\section{Casualty}

The original term (casualty) meant a seriously injured patient. It was predominantly a military word, a general term for the accidents of service: after a battle the dead, the wounded, and the sick lumped together as "casualties". The term "casual" has its origin from the workhouse "casual" who was not one of the unemployable permanents, but the irregular and unexpected caller who needed temporary help. ${ }^{3}$

The casualty ward also occurred in Shakespeare, and Dickens writing in 1837 to describe the hospital ward in which accidents were treated. ${ }^{4}$ The Lancet also described the casual ward as a ward that provided special assistance for those taken sick upon the road. It also provided shelter and accommodation for labouring man in search for work..$^{5-9}$ The early casualty departments were to treat casual attendees as well as real casualties.
In 1869, the outpatients department in St Bartholomew's was divided into two categories. The "Casualty", which comprised those who were supposed to require temporary treatment for simple diseases or injuries. And the "Outpatient" who, after receiving a regular letter of admission, was entitled to the advice of the assistant surgeons and physicians for a period of two months. The casualty patients were attended to in a new building. It consisted of a large well ventilated room, capable of seating 600 persons. The surgical casualties were seen by the house surgeon and the dressers of the inpatients, while the medical casualties were seen by the apothecaries of the hospital who were paid officials. Later the situation changed so medical casualties were seen by the house physicians in the few years before the investigation.

In the Royal Free and Great Northern Hospitals the casualty cases were attended to by the house surgeon. ${ }^{9}$

\section{The need for specialised care-early trauma services}

The care of the injured, especially those injured in battle has been one of the important stimuli to improving trauma care. The Knights of St John were said to have been taught by the Greek doctors during the Crusades, later they further developed the first aid principles and ambulance services. ${ }^{10}$

Napoleon's chief surgeon, Baron Dominique Jean Larrey (1766-1842) is credited with the concepts of; collecting and treating all the injured in an area close to the front line by quickly evacuating them by fast light horse drawn vehicles, the "Ambulances volantes". $\mathrm{He}$ also wrote his great work on military surgery Memoires de chirurgie militaire et campagnes in $1812 .{ }^{11-13}$

In civilian practice the concentration of workers involved with the creation of the great works of the Industrial Revolution led to large number of injuries and health problems. The pioneering work of Robert Jones as surgeon to the Manchester Ship Canal where with 20000 workers the accidents rate was high, was inspiring. He organised a series of first aid stations, backed up by a hospital. A resident doctor and nurses staffed each hospital. All these hospitals were connected by railway. ${ }^{14}$ 
At the outbreak of the first world war in 1914 Robert Jones became attached to the Western Command as a major. $\mathrm{He}$ was appalled by the lack of the provision for the treatment of those who suffered gunshot wounds. In 1916 he persuaded the war minister to reserve 400 military beds in Alder Hey Hospital. This was followed by the conversion of Hammersmith Infirmary into a military orthopaedic hospital. This kind of hospital started to spread all over Britain and by 1918 the army orthopaedic service had 30000 beds. ${ }^{15}$ One of the most important developments in the care of the injured was the foundation of the British Orthopaedic Association in 1918 by Robert Jones and Robert Osgood. This has created a strong cooperation between orthopaedic surgeons across the Atlantic. ${ }^{16}{ }^{17}$

The interest in trauma started to flourish and the need for a specialist service for fracture patients became a necessity. One of the early examples of specialisation in this field was the establishement of separate fracture clinics in Manchester by Harry Platt in 1913-14. ${ }^{18}$ Also, the American College of Surgeons first considered trauma care in $1922 .{ }^{19}$

In 1935 the British Medical Association Report on Fractures pointed out the deficiencies in dealing with fracture patients. There was lack of organisation and continuity of care. Patients were admitted under the nominal charge of a surgeon who took little interest in such cases. These cases were delegated usually to the house surgeons. There was also no proper rehabilitation after discharge.

The recommendations were that a "casualty officer" should examine patients with ambulatory fractures and provide initial management. A "chief assistant" then would see patients the next day in the daily clinic. Inpatients fractures admitted through casualty or outpatients would be seen by the house surgeons if uncomplicated. Complicated and compound fractures were to be dealt with as emergencies. They were to be treated in operating theatre by the surgeon or chief assistant. After discharge they were be followed up in the outpatient department. $^{2021}$

Later in 1943 The British Orthopaedic Association in its Memorandum on Accident Services emphasised that accident services of the future should embrace the treatment of fractures as well as soft tissue injuries, infections, and all other injuries of the locomotor system. They also believed that accident services must be developed by surgeons who have been trained and qualified to deal with trauma. ${ }^{22}$

One of the prominent landmarks in dealing with trauma was the development of Birmingham Accident Hospital in 1941. The hospital was established to deal with the rapidly increasing road traffic and industrial accidents. The pioneer of the project was Professor William Gissane. The hospital looked after all sorts of injury including victims of air raids during the war. The hospital provided continuous cover with a full time consultant surgeon, 24 hour radiography, and blood transfusion, and a mobile operating theatre (surgical unit) that was based at the hospital. ${ }^{23}$ Within one year of its foundation the Birmingham Accident Hospital attracted the interest of the Medical Research Council under the direction of Sir Ashley Miles. There was an ambitious research project studying wound infection and the first controlled trial of penicillin in local infection was undertaken. ${ }^{24}$

The idea of a separate accident hospital was extremely innovative but the isolation of the unit from other acute specialties led to problems. Professor Gissane planned to associate the hospital more closely with special units. These plans were shelved because of a lack of funds. ${ }^{25}$

The National Health Service in July 1948 inherited a large number of casualty departments, most of them in substandard accommodation. The staffing was poor, with absent support from seniors who were in nominal charge only- "absentee landlords" as called by Maurice Ellis. ${ }^{11}$ As most of the departments were not planned or staffed adequately, the situation became serious and the level of care was below the expected standard. In 1959 the British Orthopaedic Association Memorandum on Accident Services recommended that regional hospital boards, in association with teaching hospital boards, set up at least one comprehensive accident service within its area. It was hoped that such units would integrate to form a nationwide accident service. They were in favour of having accident units that were part of a general hospital. Orthopaedic surgeons should be in charge, as the locomotor system accounted for three quarters of all injuries. ${ }^{26}$

This was the probably the beginning of the structure of the modern UK service of the "DGH A\&E".

The Nuffield Provincial Report (1960) showed that the casualty services in the studied areas were still badly housed in unplanned accommodation. The staffing was inadequate with juniors receiving very little support from seniors. The main duties of the consultant in charge were to plan the rota and to do pre-planned clinics. The majority of the departments received low rating in all aspects apart from the quality of the casualty sisters. ${ }^{27} 28$

Concerns had increased over the level of care provided for the seriously ill and injured patients. These concerns and the desire to improve the service initiated the subcommittee report prepared by Sir Harry Platt, the first meeting was held on 20 April 1960. They met 19 times until the production of their package of recommendations.

\section{The birth of A\&E-The Platt Report ${ }^{4}$}

Sir Harry Platt, the chairman of the Accident and Emergency Services Sub-Committee of the Standing Medical Advisory Committee, produced the famous report in 1962 (fig 1).

Clarkson expressed similar opinions in 1960 writing in the Guy's Hospital Gazette. He said that casualty departments should act as a receiving room for the "acute sick" as well as for accident cases, also segregation of cases 


\section{The Platt Report}

• The name "casualty service" should be altered to "accident and emergency service."

- Every major accident and emergency unit should have three consultant surgeons (orthopaedic) devoting substantial part of their time to the unit, and be supported by adequate number of intermediate and junior medical staff.

- The department should receive all undiagnosed medical emergencies as well as accident victims.

- Injured patients should be taken to the department that is staffed and equipped to deal efficiently with the type and severity of their injuries, not to the nearest one.

- The departments should be purpose built.

- Separate provision must be made for treatment of minor non-traumatic conditions however this should not interfere with care of seriously ill. This could be provided in hospitals with non-designated departments.

- The care of accident patients should be in general hospitals where all specialities are available.

- Minor cases could be reduced by the provision of GP services.

- Rotation of the medical staff between $A / E$ and general surgical work is valuable particularly at registrar level.

- There should be adequate nursing staff, radiographers, secretarial, receptionists and other supporting services.

- The number of the departments should be reduced. Each unit should not normally serve a population of less than 150000 .

Figure 1 The Platt report.

should occur inside the department not at the hospital gate. ${ }^{30}$ Such "medical" cases had been part of the workload of many "casualty" departments. ${ }^{31}$

With all the positive changes recommended in the Platt report unfortunately there was no provision for creating senior career posts for the newly named department. A few departments, such as Leeds General Infirmary, had appointed senior doctors to run the $A \& E$ department (Morris Ellis 1949) and in others experienced doctors became the leaders of departments although many did not have

\section{The Clark Report}

1 The committee strongly supported the inclusion of accident work within the

early post registration rotation, for Senior House Officers they recommended a series of

six month periods in different specialties, one of which might be accident work. For

surgical registrars they recommend that they spend six months of their rotation in

accident and emergency.

2 Senior registrars from surgical or medical specialties should be allowed to

obtain experience in accident work, should they desire to do so.

3 Every student must spend officially prescribed time in an accident unit.

4 The report also recommends in detail the design of accident units; also

special supporting services availability such as laboratory and rehabilitation facilities.

Figure 2 The Clark report. consultant status. These doctors saw that running an $A \& E$ department required different skills from orthopaedic surgery and this was one of the main driving forces for the formation of the Casualty Surgeons Association in 1967. It was supported by the acceptance of the Department of Public Health that casualty departments needed to be supervised by consultants dedicated to the specialty and providing shop floor leadership and supervision. The main aim of the Association was to form a professional body to further the standard of $\mathrm{A} \& \mathrm{E}$ care. $\mathrm{Mr} \mathrm{M}$ Ellis was then elected as president in the first annual general meeting held in the Walsall General Hospital on the 23 of March $1968 .^{32}$

Concerns about difficulties in staffing departments increased. Some felt that the creation of dedicated consultant posts in busy departments would improve the service and encourage appointments at assistant grade.

Others felt that the creation of career grades should be at all levels and the consultant in charge trained in both general and orthopaedic surgery. Also improving work conditions was essential as bad conditions led to poor quality work and a difficulty in recruiting doctors. ${ }^{33-35}$

Many hospitals tried to overcome the staffing problem by appointing senior hospital medical officers, but the job was regarded as a "dead end". And upgrading of this post was not considered. ${ }^{36}{ }^{37}$ The shortage of juniors in the casualty department was almost national. Only famous hospitals were not affected. ${ }^{38}$ Even at that time litigation was perceived as a major problem that made $A \& E$ work difficult and unattractive. ${ }^{39-43}$

However, many were still resistant to any changes in the pattern of department staffing, believing that "casualty work" was not a specialty. ${ }^{44} 45$

Nationally there was no fixed strategy for staffing. Some hospitals employed full time casualty officers, while in others casualties used to be seen by resident house staff as part of their routine duties. ${ }^{46}$

In response to these difficulties the accident services review committee (Chairman Sir H Osmond Clark 1970), ${ }^{47}$ after a series of investigations, reported that staffing was still inadequate. Although orthopaedic consultants were in nominal charge they were busy with their specialty and found it difficult to devote enough time to shop floor commitment. There was also difficulty in appointing experienced middle grade doctors, and registrars had to be called away from other work to cover the department.

Most departments were still in old accommodation, there was little room for expansion, and the facilities were appalling (fig 2).

\section{The emergence of $A \& E$ medicine as a} specialty

In 1971 the Joint Consultants Committee set up a subcommittee to investigate "the problem" under the chairmanship of Sir John Bruce. ${ }^{48}$ The key recommendation of this report was the experimental appointment of 32 consultants in "Accident and Emergency" to 
work full time in major departments. Later in 1974 The Department of Health reported "In no instance has an appointment failed to achieve some positive benefit. In a number of instances there have been significant improvements in the organisation of the accident and emergency services in its wider connotation".

There were earlier calls for appointing seniors at consultant level in 1966, the Lancet reported that the appointment of the dedicated consultants was approved. It was the Joint Consultant Committee and the Health Departments views that some $\mathrm{A} \& \mathrm{E}$ departments should be the responsibility of a consultant who gave all his time to this work, they also made it possible for senior casualty officers to apply. $^{49}$

The number of consultant appointments started to increase, and by 1976 there were 105 consultants in post, most of them had been working in a variety of non-consultant posts, having chosen $\mathrm{A} \& \mathrm{E}$ as a career. ${ }^{11}$

Some enthusiastic committed doctors began to design their own training schemes and a few undertook research leading to an $\mathrm{MD}$, a considerable achievement at the birth of a specialty. By the mid 1970s it was evident that there was an urgent need to formalise training of consultants and the Specialist Advisory Committee in $\mathrm{A} \& \mathrm{E}$ medicine was established and a training programme designed. The first senior registrar appointment was in 1977. The number of consultants and trainees continued to increase and by 1997 there were almost 400 consultants and over $269 \mathrm{SpRs}$ in post. ${ }^{50}$

Emergency medicine around the world ${ }^{5152}$ Clinicians all over the world desire to provide the highest quality of emergency care to combat the increasing death rate from injuries as a result of rapid urbanisation and industrialisation.

Examining the emergency care in the developed countries we find that it is practised mainly in two models.

THE ANGLO-AMERICAN MODEL

This is practised in UK, ${ }^{53}$ USA, Ireland, Australia, ${ }^{54}$ New Zealand, Canada, Japan, Taiwan, South Korea, and Israel. ${ }^{51}{ }^{52}$

The care of emergency patients is provided by specially trained hospital based doctors who deliver a wide range of services for all patients presenting to a separate emergency department. Emergency medicine in these countries is a recognised independent specialty with professional associations. There is a structured training programme for trainees, and recognised qualifications.

THE FRANCO-GERMAN MODEL ${ }^{55} 56$

This is practised mainly in Germany, France, and other European countries including Russia. $^{57}$

In Germany emergency medicine is not a recognised specialty, and there is a strong resistance to its creation. Most doctors practising emergency medicine are from specialties such as anaesthesia, surgery, and medicine. The situation is similar in France where the specialty does not exist and most practising physicians comes from other specialties. In Switzerland ${ }^{58}$ emergency medicine is not an autonomous specialty and there is no representing official medical association. The Russian and the eastern European systems are more similar to the Franco-German model. In this model the initial resuscitation is delivered by anaesthetist; this is followed by direct triage to a specialty. Recently, emergency medicine in Italy, which was regarded organisationally as a branch of general medicine, has changed. ${ }^{59}$ In 1996 a training programme started in emergency medicine with a shift from the FrancoGerman system to the Anglo-American one.

\section{EMERGENCY MEDICINE IN THE DEVELOPING} COUNTRIES

Many countries have realised the need for emergency medicine while others have different priorities and no one model fits all health systems. In Hong Kong ${ }^{60}$ the first consultant appointment in emergency medicine was in 1981 with the creation of The Society for Emergency Medicine in 1985. In Singapore ${ }^{61}$ emergency medicine has been a specialty since 1984 with a structured training programme started in 1989. In South Korea ${ }^{62}$ emergency medicine has been a recognised specialty since 1996 with a training programme and board certification. In China ${ }^{63}$ the need for emergency medicine as a specialty was realised with growing industrialisation. The specialty is beginning to be recognised and a five year training residency programme has started. In Nicaragua $^{64}$ emergency medicine training started in 1993, a residency programme designed on the American model followed by a written and oral examination with a diploma of specialty awarded to who pass.

In India, ${ }^{65}$ Thailand, ${ }^{66}$ South Africa, ${ }^{67}$ Namibia, ${ }^{68}$ Madagascar, ${ }^{69}$ Lebanon, ${ }^{70}$ and Jordan $^{71}$ the situation is different. In India emergency medicine is not a specialty. The service is provided in "Casualty Centres" staffed by physicians who have no postgraduate qualifications and the post is temporary in most circumstances. Ambulances are privately owned and operate on a fee for service base. In Thailand the departments are poorly staffed, particularly after working hours and in rural areas (young staff and old equipments). In South Africa emergency medicine is not a specialty, doctors working in the emergency departments are called "Casualty Officers" most of them have never had specialty training. A new specialty diploma has been introduced but most of those who hold the diploma work in private hospitals.

In Namibia, Madagascar, Lebanon and Jordan the post in the emergency department is temporary, on call staff physicians are summoned if patients present after clinics.

\section{The future}

At the start of the millennium the challenges facing $A \& E$ departments continue to grow and so the specialty must grow to meet these demands. It is important to remember the reasons for the foundation of the specialty, a 
need to have properly trained consultants organising, supervising and training those involved in the delivery of care to patients attending the A\&E department. This work needs to have the priority; work that cannot be carried out without presence in the department and on the "shop floor". However, the casemix of $\mathrm{A} \& \mathrm{E}$ is changing. Patients with serious medical conditions outnumber those with serious injury by 8 to 1 . Even with minor injury we see a change in casemix with many elderly people attending with minor falls, many of which are attributable to other medical problems. $^{72}$

Patients are more likely to come with other health problems that will influence management. The expectations of the public and increasingly of the profession are that we can always "get it right" first time.

What will be the changes to our specialty in the next 10-15 years? Demands will continue to increase. There will be more patients, with more serious illness and higher expectations. There will continue to be pressure on hospital beds. More elderly people will be living alone on the margins of safety in the community with the $A \& E$ department as a key source of help.

It would be foolish to try and tackle all these needs from within the specialty. Different models of diverting demand have been suggested, such as NHS Direct. At present there is little if any evidence that schemes such as NHS Direct will reduce A\&E workload. We should continue to work with primary care, social work and other community services to try to ensure that the correct response to emergency health and social needs are adequately met. In some areas the concept of local primary care emergency centres and minor injury units will probably gain strength and popularity. They may be more expensive than A\&E care but they fulfil most of the emergency health needs for populations of 50-100 000. These centres, if properly set up, can probably deal with $30-40 \%$ of the patients arriving in our departments. If this more minor workload is removed then the A\&E department will be left with a marked increase in the complexity of the work it does. The patient mix will be heavily biased to acute general medicine and the "difficult" musculoskeletal problems that are too complex for the minor injuries unit or general practice. However, in many areas with lower populations the $\mathrm{A} \& \mathrm{E}$ department will continue to provide all these services.

The increasing specialisation of other hospital specialists is leaving a gap in health care. We have seen that general surgeons feel that they no longer have the skills to observe minor head injury. A\&E specialists probably have the skills to care for such patients. There is an emerging vacuum in acute care and it is for our specialty to choose paths to develop.

The initial assessment and early treatment in resuscitation, trauma, medical and paediatric emergency will remain the "core" role of the $\mathrm{A} \& \mathrm{E}$ practitioner. If there is an increasing need to take over more of the care of patients for longer periods of their illness then we must start to plan now to develop the skills and experience to deal with them. This process is already well underway with more trainees entering the specialty with a general $A \& E$ training or general medical training often with anaesthetic/ITU bias. We should start to identify some specific gaps in training and perhaps to restructure training programmes to ensure the necessary skills are obtained.

Equally important we need to start to realise that consultants and staff grades already in post need to acquire some new skills. The process of continuing professional development should identify gaps in training and skills. The crunch will come when time has to be found to allow senior staff sabbaticals and "secondments". It is naive to think that the average senior will be able to find the time for such extra training in an already over committed schedules. However, if "consultant appraisal" and "continuing professional development" are to have real impact then it is clear that time and money must be found to allow the acquisition and retention of new skills.

Having identified the skills, what working patterns will be required? The present consultant led service, a 24 hour consultant led service or a service where all care is provided by permanent staff (including nurse practitioners)? This is a key question for our specialty. There is little good evidence on the best model. Any change from the present model is going to be more expensive. Experience from systems that have full 24 hour $A \& E$ specialist provision suggests that retention of staff is an increasing problem and that it may be difficult to maintain such patterns with increasing years. There is simply not enough evidence on outcomes, costs and human resource issues to make "evidence based policy" on this issue.

There is so much work that we know that we can do better than the current system and many have an almost evangelical zeal to improve the care of the critically ill patient. However, we must not forget that increases in the services to one part of our workload should not decrease the level of service to other patients in our departments. Expansion of responsiblity needs more manpower, to neglect this very obvious statement risks the overwork of those currently providing the service. Many departments are at present struggling to cope with current workloads. Many are experiencing increased waiting times especially for minor injuries. More resources are the key to any development and given our key position in emergency care we are in a very good position to make a strong case of need.

Throughout this paper the specialty has been referred to as $\mathrm{A} \& \mathrm{E}$ medicine. Increasingly emergency medicine is being used as a title for consultants and to describe departments. There is much debate on whether we should formally change. We do see and treat both accidents and emergencies. The public has a growing respect for the specialty and the recent high profile "A\&E modernisation" initiative has further cemented the title as "A\&E". Yet it is probably only a matter of time until the groundswell of opinion from within the specialty forces a change. We practise the most 
acute parts of "medicine" in its widest context including medicine, surgery, anaesthesia, paediatrics, psychiatry. Our specialty, where it exists in the rest of the world is called emergency medicine. It is clear that if in the future we might want to change the name of our specialty then we should delay debate no longer.

Whatever the future brings we should remember the reason for our success as a specialty, the ability to provide a presence, when needed, at the front door of the hospital for all the many and different emergency health needs that patients bring to our departments. Over the past 25 years we have been developing the systems, the flexibility and breadth of training to cope with these demands. Any development should not detract from these core aims or we might find ourselves specialising to such an extent that we are no longer available "on the shop floor" for the next difficult case and we will have lost the main reason for the success of our specialty.

Contributors

MS wrote the early drafts of the paper and carried out most of the research. JW contributed many of the ideas and advised on the structure and content and helped write the definite manuscript and revise the paper.

Funding: none.

Conflicts of interest: none.

1 Lowden TG. The casualty department, the work and the staff. Lancet 1956;i:955-6.

2 Bache J. Accidents and emergencies. 6th ed. Oxford: Oxford Medical Publications, 1994

3 Ell B. Casuals and casualties. Medical idioticon. Lancet $1972 ; \mathrm{i}: 1113$

4 Platt H. Report Of The Standing Medical Advisory Committee, Accident And Emergency Services. London: HMSO, 1962.

5 The Lancet investigation into the administration of the outpatient department of the London hospitals No 2 . St Bartholomew's Hospital. Lancet 1869;ii:577-9.

6 The Casual Wards Bill. Lancet 1892; ii: 1433.

6 The Casual Wards Bill. Lancet 1892;ii:1433.
7 The treatment of "casuals". Lancet 1892;ii:757.

7 The treatment of "casuals". Lancet $1892 ;$;ii: 757 .

8 The treatment of a "casualty patient". Lancet 1869;ii:732. patient department of the London hospitals No 4. Lancet patient departme

10 Fitzgerald G. Setting the scene: the history and development of emergency medical service. F Emerg Med 1998;16:309.

11 Wilson DH. The development of accident and emergency medicine. Community Medicine 1980;2:28-35.

2 Guthrie D. A history of medicine. London: Thomas Nelson, 1960:338-40.

13 Cone DC. Emergency medical services. In: Plantz SH, Adler $\mathrm{N}$, eds. Emergency medicine. Baltimore: Williams and Wilkins, 1998.

14 Court-Brown CM. Treatment of the polytraumatized patient in the UK. Clin Orthop 1995;318:36-42.

15 McInnes EM. St Thomas' Hospital. 2nd ed. London: Special

16 Jones AR. The British Orthopaedic Association: a founder's Jones AR. The British Orthopaedic Associa

17 Barnes R. British Orthopaedic Association: fifty years, editorial and annotations. F Bone foint Surg 1968;50-B 691-8.

18 Le Vay D. The history of orthopaedics. Carnforth: The Parthenon Publishing Group, 1990:145.

19 Cales R, Trunkey D. Preventable trauma deaths. A review of trauma care systems development. $\mathcal{F} A M A$ 1985;254:105963.

20 British Medical Association. Report of Committee on Fractures. BMF 1935:i (suppl):53.

21 British Medical Association. Report Of Committee on Fractures. BMf 1935;i (suppl):308-9.

22 British Orthopaedic Association. Memorandum on accident services. London: British Orthopaedic Association, 1943.

$23 \mathrm{Sir}$ Robert Hunter introduction in honour of professor W Gissane. Injury 1978;10:5-6.

24 Harrison S H. Accident surgery-the life and times of William Gissane. Injury 1984;16:145-54.

25 London PS. Personal reminiscences of W Gissane by past and present colleagues. Injury 1978;10:7-9.

26 British Orthopaedic Association. Memorandum on accident services. London: British Orthopaedic Association, 1959.
27 Nuffield Provincial Hospitals Trust. Casualty services and their setting. A study in medical care. London: Oxford University Press, 1960.

28 Anon. Casualty departments. Lancet 1960;ii:689-90.

29 Anon. Accident services. Lancet 1962;ii:500.

30 Clarkson P. Casualty departments. Lancet $1961 ; \mathrm{i}: 348$.

1 Ellis M. The casualty officers handbook. London: Butterworths, 1962

32 British Association for Accident and Emergency Medicine Directory. London: Lavenham Press, 1996.

33 Scott JC. Accident and emergency services. BMF 1965;ii: 1371

34 Garden RS. The casualty department and the accident service. Lancet 1965;i:901-3.

35 Clarkson P. Casualty departments in teaching hospitals. Lancet 1956;ii:31-5.

36 Anonymous. Poor service in casualty. BMF 1960;ii:920-1.

37 Abson EP, Caro DB. Senior casualty officers. BMF 1965;ii: 941.

38 Burrough EJR. Unity in diversity. The short life of the United Oxford Hospitals. Privately printed, 1978. (Available from the Royal College of Surgeons of England.)

39 Insurance for casualty surgeons. BMY 1964;ii: 1406

40 Lowden TG. The casualty department, II. Shortcomings and difficulties. Lancet 1956;i:1006.

41 Corbally E. Responsibility for casualties. Medicine and the law. Lancet 1967; ;i:1142-3.

42 Rose I. The casualty department. Lancet 1956;ii:308.

43 Corbishley K. Shortage of casualty officers. Lancet 1953;ii: 454.

44 Ekin WH, Wilson JW. Accident and emergency services. BMF 1965;ii: 1436.

45 Gee A. Junior hospital staff. Lancet 1953;i:696-7.

46 Anonymous. Children in casualty. Lancet 1966;i:246.

47 Accident Services of Great Britain and Ireland. Second Report of Review Committee. Sir H Osmond-Clarke. Report Of A Working Party on Progress the Provision of Accident Services. London: BMA, 1970

48 Joint Consultants Committee (Chairman: Sir John Bruce). Report Of A Joint Working Party, 1971.

49 Anonymous. Casualty, accident, and emergency departments. Lancet 1966;i:933.

50 British Association for Accident and Emergency Medicine. The way ahead. London: British Association for Accident and Emergency Medicine, 1997.

51 Kirsch TD. Emergency medicine around the world. Ann Emerg Med 1998;32:237-8.

52 Arnold JL. International emergency medicine and the recent development of emergency medicine worldwide. Ann Emerg Med 1999;33:97-103.

53 McHugh DF, Driscoll PA. Accident and emergency medicine in the United Kingdom. Ann Emerg Med 1999;33:702-9.

54 Cameron PA, Bradt DA, Ashby R. Emergency medicine in Australia. Ann Emerg Med 1996;28:342-6.

55 Nikkanen HE, Pouges C, Jacobs LM. Emergency medicine in France. Ann Emerg Med 1998;31:116-20.

56 Moecke H. Emergency medicine in Germany. Ann Emerg Med 1998;31:111-15.

57 Townes DA, Lee TE, Gulo S, VanRooyen MJ. Emergency medicine in Russia. Ann Emerg Med 1998;32:239-42.

58 Osterwalder JJ. Emergency medicine in Switzerland. Ann Emerg Med 1998;32:243-7.

59 Repetto C, Casagranda I, Overton D, et al. Emergency medicine: the Italian experience. Ann Emerg Med 1998;32: 248-52.

$60 \mathrm{Fu}$ tat El, Chan $\mathrm{KH}$, VanRooyen MJ. Emergency medicine in Hong Kong. Ann Emerg Med 1998;32:83-5.

$61 \mathrm{Lim} \mathrm{SH}$, Anantharaman V. Emergency medicine in Singapore: past, present, and future. Ann Emerg Med 1999; 33:338-43.

62 Arnold JL, Song HS, Chung JM. The recent development of emergency medicine in South Korea. Ann Emerg Med 1998;32:730-5.

63 Clem KJ, Thomas TL, Wang Y-T, Bradley D. United States physicians assistance in development of emergency medi-
cine in Hangzhou, China. Ann Emerg Med 1998;32:86-92.

64 Gaitan m, Mendez W, Sirker NE, et al. Growing pains: status of emergency medicine in Nicaragua. Ann Emerg Med 1998;31:402-5.

65 Alagappan K, Cherukuri K, Narang V, et al. Early development of emergency medicine in Chennai (Madras), India. Ann Emerg Med 1998;32:604-8.

66 Church AL, Plitponkarnpim A. Emergency medicine in Thailand. Ann Emerg Med 1998;32:93-7.

67 Clarke ME. Emergency medicine in new South Africa. Ann Emerg Med 1998;32:367-72.

68 Tintinalli J, Lisse E, Begley A, et al. Emergency medicine in Namibia. Ann Emerg Med 1998;32:373-7.

69 Ramalanjaona G. Emergency medicine in Madagascar. Ann Emerg Med 1998;31:766-8.

70 Musharafieh R, Bu-Haka R. Development of emergency medicine in Lebanon. Ann Emerg Med 1996;28:82-6.

71 Abbadi S, Abdallah AK, Holliman CJ. Emergency medicine in Jordan. Ann Emerg Med 1997;30:319-21.

72 Close J, Ellis M, Hooper R, et al. Prevention of falls in the elderly trial (PROFET): a randomised controlled trial. Lancet 1999;353: 93-7. 